\title{
Review \\ Clinical review: Timing and dose of continuous renal replacement therapy in acute kidney injury
}

\author{
Paul M Palevsky
}

Renal Section, VA Pittsburgh Healthcare System, Pittsburgh, PA 15240, and Renal-Electrolyte Division, Department of Medicine, University of Pittsburgh School of Medicine, Pittsburgh, PA 15261, USA

Corresponding author: Paul M Palevsky, palevsky@pitt.edu

Published: 6 November 2007

This article is online at http://ccforum.com/content/11/6/232

(C) 2007 BioMed Central Ltd.
Critical Care 2007, 11:232 (doi:10.1186/cc6121)

outcomes of $\mathrm{AKI}$ and that optimization of renal support may reduce its high mortality [6-8]. Recent studies have suggested that more intensive dosing of both continuous $[9,10]$ and intermittent [11] RRT are associated with reductions in mortality; however, results have not been consistent across all studies [12] and these findings have not been widely applied in clinical practice [13]. Although this review focuses on the issue of timing and dose of continuous RRT (CRRT), summarizing recent data and suggesting avenues for future research, it should be recognized that many of the same issues apply to the management of intermittent hemodialysis in AKI. The related issue of modality of renal support, the subject of multiple recent studies [14-17], is beyond the scope of this review, and has been reviewed and debated elsewhere [18-22].

\section{Timing of initiation of continuous renal replacement therapy}

Although the focus of this review is on CRRT, a brief summary of data regarding the initiation of intermittent hemodialysis in AKI is informative. The concept of prophylactic hemodialysis in AKI was introduced by Teschan and colleagues more than 50 years ago $[23,24]$. A series of retrospective case series and observational studies conducted from the 1950s through the early 1970s compared 'early' initiation of hemodialysis, as defined by blood urea nitrogen (BUN) concentrations ranging from $<93 \mathrm{mg} / \mathrm{dl}$ to levels of approximately $150 \mathrm{mg} / \mathrm{dl}$, to 'late' initiation of therapy, as defined by BUN levels of $163 \mathrm{mg} / \mathrm{dl}$ to $>200 \mathrm{mg} / \mathrm{dl}$ [25-27]. These studies (Table 1) all demonstrated improved survival with earlier initiation of hemodialysis. Two prospective clinical trials comparing early to late initiation of hemodialysis in AKI were conducted during the 1970 s and 1980 s $[28,29]$. In the first of these prospective trials, 18 patients with posttraumatic AKI were alternately assigned to an intensive dialysis regimen to maintain the pre-dialysis BUN at

$\mathrm{AKI}=$ acute kidney injury; $\mathrm{BUN}=$ blood urea nitrogen; CRRT = continuous RRT; CVVH = continuous venovenous hemofiltration; CVVHDF $=$ continuous venovenous hemodiafiltration; ICU = intensive care unit; IHD = intermittent hemodialysis; RRT = renal replacement therapy. 


\begin{tabular}{|c|c|c|c|c|c|c|c|c|}
\hline \multirow[b]{2}{*}{ Study } & \multirow[b]{2}{*}{ Year } & \multirow[b]{2}{*}{ Mode of RRT } & \multirow[b]{2}{*}{ Study design } & \multirow[b]{2}{*}{$\mathrm{N}$} & \multicolumn{2}{|c|}{ BUN at initiation of RRT $(\mathrm{mg} / \mathrm{dl})$} & \multicolumn{2}{|c|}{ Survival (\%) } \\
\hline & & & & & Early & Late & Early & Late \\
\hline Parsons et al. [25] & 1961 & IHD & Retrospective & 33 & $120-150$ & $>200$ & 75 & 12 \\
\hline Fisher et al. [26] & 1966 & IHD & Retrospective & 162 & $\sim 150$ & $>200$ & 43 & 26 \\
\hline Kleinknecht et al. [27] & 1972 & IHD & Retrospective & 500 & $<93$ & $>163$ & 73 & 58 \\
\hline Conger [28] & 1975 & IHD & RCT & 18 & $<70$ & $\sim 150$ & 64 & 20 \\
\hline Gillum et al. [29] & 1986 & IHD & RCT & 34 & $<60$ & $\sim 100$ & 41 & 53 \\
\hline Gettings et al. [31] & 1999 & CRRT & Retrospective & 100 & $<60$ & $>60$ & 39 & 20 \\
\hline Bouman et al. [12] & 2002 & CRRT & RCT & 106 & $\begin{array}{l}\text { LV: } 48(40-66)^{\mathrm{a}} \\
\text { HV: } 46(38-58)^{\mathrm{a}}\end{array}$ & LV: $105(62-116)^{a}$ & $\begin{array}{l}\text { LV: } 69 \\
\text { HV: } 74\end{array}$ & LV: 75 \\
\hline Demirkiliç et al. [32] & 2004 & CRRT & Retrospective $^{b}$ & 61 & NS & NS & 77 & 45 \\
\hline Elahi et al. [33] & 2004 & CRRT & Retrospective $^{b}$ & 64 & $67 \pm 35^{c}$ & $75 \pm 61^{c}$ & 78 & 57 \\
\hline Piccinni et al. [34] & 2006 & CRRT & Retrospective $^{d}$ & 80 & NS & NS & 55 & 28 \\
\hline Liu et al. [35] & 2006 & IHD and CRRT & Observational & 243 & $\leq 76$ & $>76$ & 65 & 59 \\
\hline
\end{tabular}

aMedian blood urea nitrogen (BUN; quartiles). ${ }^{b} \mathrm{RRT}$ started based on urine output $<100 \mathrm{ml}$ over 8 hours in early group and based on biochemical parameters in late group. 'Mean BUN \pm standard deviation. dPatients with sepsis and oliguria; RRT started within 12 hours of ICU admission in early group and based on 'conventional indications'. CRRT, continuous renal replacement therapy; HV, high-volume hemofiltration; IHD, intermittent hemodialysis; LV, low-volume hemofiltration; NS, not specified; RCT, randomized controlled trial; RRT, renal replacement therapy.

$<70 \mathrm{mg} / \mathrm{dl}$ and the serum creatinine at $<5 \mathrm{mg} / \mathrm{dl}$, or to a nonintensive regimen in which dialysis was not provided until the BUN approached $150 \mathrm{mg} / \mathrm{dl}$, the creatinine reached $10 \mathrm{mg} / \mathrm{dl}$, or clinical indications for dialysis were present [28]. Survival was $64 \%$ (5 of 8 patients) in the intensive treatment group compared to $20 \%$ ( 2 of 10 patients) with the non-intensive dialysis strategy $(p<0.10$ but $>0.05)$. In addition, major complications, including hemorrhage and Gram-negative sepsis were less frequent in the intensive hemodialysis arm. The second of these two prospective studies entailed 34 patients who were stratified based on the etiology of AKI and randomized in a paired fashion [29]. Patients were enrolled when the serum creatinine reached approximately $8 \mathrm{mg} / \mathrm{dl}$ and were dialyzed to maintain a predialysis BUN of $<60 \mathrm{mg} / \mathrm{dl}$ in the intensive treatment arm and approximately $100 \mathrm{mg} / \mathrm{dl}$ in the non-intensive arm. The average time to initiation of dialysis was $5 \pm 2$ days in the intensive arm and $7 \pm 3$ days in the non-intensive arm. Mortality was higher in the less intensively dialyzed group; however, given the small sample size, this difference was not statistically significant.

On the basis of these data, conventional teaching has been that in the absence of specific symptoms, hemodialysis should be initiated when the BUN reaches a level of approximately $100 \mathrm{mg} / \mathrm{dl}$, but that no additional benefit is associated with earlier initiation of therapy. It should be recognized, however, that the study on which this argument is based had inadequate statistical power to draw definitive conclusions. It has also been argued that a strategy of early initiation of dialysis might subject patients to the risks of hemodialysis who would recover renal function with conservative therapy alone and that exposure to hemodialysis might delay recovery of renal function and adversely impact patient survival [30].

Several studies over the past decade have evaluated the impact of timing of initiation of CRRT on outcomes of AKI. In the first of these studies, Gettings and colleagues [31] retrospectively analyzed the timing of initiation of continuous venovenous hemofiltration (CVVH) on outcomes in patients with post-traumatic AKI by stratifying 100 consecutive patients based on the BUN at initiation of treatment. 'Early' and 'late' initiation of therapy were defined by stratifying patients using the BUN at initiation of therapy, using a value of $60 \mathrm{mg} / \mathrm{dl}$ to separate the two groups. In the 'early' group, CVVH was initiated on hospital day $10 \pm 15$, with a mean BUN of $43 \pm 13 \mathrm{mg} / \mathrm{dl}$ compared to the 'late' group, in whom treatment was initiated after $19 \pm 27$ days with a mean BUN of $94 \pm 28 \mathrm{mg} / \mathrm{dl}$. Survival was $39 \%$ in the 'early' initiation group, compared to $20 \%$ in the 'late' group $(p=0.041)$. Although baseline demographic characteristics and severity of illness scores of patients in the two groups were comparable, a greater percentage of patients in the late cohort had multisystem organ failure or sepsis. In addition, details of why RRT was initiated earlier as opposed to later were not provided and may have contributed to unrecognized differences between the two cohorts. 
Similar results have been reported in two retrospective analyses of timing of CRRT in patients following cardiac surgery [32,33]. Demirkiliç and colleagues [32] reported on a series of 61 patients undergoing cardiac surgery at a single center in Turkey between March 1992 and September 2001 who received postoperative continuous venovenous hemodiafiltration (CVVHDF). In the 27 patients treated before June 1996, CVVHDF was started when the serum creatinine level exceeded $5 \mathrm{mg} / \mathrm{dl}$ or the serum potassium level exceeded $5.5 \mathrm{mEq} / \mathrm{l}$ despite medical therapy, independent of urine output (group 1); in the remaining 34 patients treated after June 1996, CVVHDF was initiated if the urine volume was less than $100 \mathrm{ml}$ over 8 hours despite administration of furosemide (group 2). Treatment was initiated $2.6 \pm 1.7$ days after surgery in group 1 compared to $0.9 \pm 0.3$ days in group 2. Early initiation was associated with lower ICU $(17.6 \%$ versus $48.1 \% ; p<0.05)$ and hospital mortality $(23.5 \%$ versus $55.5 \% ; p<0.05)$ and decreased duration of both mechanical ventilation and ICU length of stay. Similarly, Elahi and colleagues [33] identified 64 consecutive patients who underwent cardiac surgery between January 2002 and January 2003 in a single center in the United Kingdom and who were treated with post-operative CVVH. In 28 patients, CVVH was not initiated until the BUN was at least $84 \mathrm{mg} / \mathrm{dl}$, the creatinine was at least $2.8 \mathrm{mg} / \mathrm{dl}$ or the serum potassium was greater than $6 \mathrm{mEq} / \mathrm{l}$ despite medical therapy, regardless of urine output (group 1), while in the remaining 36 patients CVVH was initiated if the urine volume was less than $100 \mathrm{ml}$ over 8 hours despite furosemide infusion (group 2). As in the prior study, the reported demographic and baseline clinical characteristics of the two groups were similar. The interval between surgery and initiation of renal support was $2.6 \pm 2.2$ days in group 1 compared to $0.8 \pm 0.2$ days in group 2 . Hospital mortality was $43 \%$ in group 1 and $22 \%$ in group 2 $(p<0.05)$. Similar results have been reported by Piccinni and colleagues [34] in an analysis of 40 consecutive oliguric patients with sepsis treated with early isovolemic hemofiltration compared to 40 consecutive historical controls. Twenty-eight day survival in the patients treated with isovolemic hemofiltration was 55\% compared to $27.5 \%$ in the historical control cohort.

In another retrospective analysis, Liu and colleagues [35] analyzed data on the timing of initiation of renal replacement therapy (both intermittent hemodialysis (IHD) and CRRT) from the Program to Improve Care in Acute Renal Disease (PICARD), a multicenter observational study of AKI. The 243 patients in the database who received RRT were stratified into 'early' and 'late' initiation groups based on the median BUN $(76 \mathrm{mg} / \mathrm{dl})$ at initiation of therapy. Although patients in the 'late' (BUN $>76 \mathrm{mg} / \mathrm{dl}$ ) group had a reduced burden of organ failure, the survival rates at 14 days and 28 days in this group ( 0.75 and 0.59 , respectively) were slightly lower than in the 'early' (BUN $\leq 76 \mathrm{mg} / \mathrm{dl}$ ) group $(0.8$ and 0.65 , respectively). After adjustment for age and clinical factors and stratification by site and initial modality of RRT in a multi- variate analysis, the relative risk of death associated with dialysis initiation with a higher degree of azotemia (using the 'early' initiation group as the comparator) was 1.85 (95\% confidence interval 1.16 to 2.96). Similarly, using a propensity score analysis to adjust for factors predicting initiation of therapy at a higher compared to a lower BUN, the relative risk in the high BUN group was 2.07 (95\% confidence interval 1.30 to 3.29 ). Combining the multivariate adjustment and the propensity score yielded an adjusted relative risk of 1.97 (95\% confidence interval 1.21 to 3.20 ).

There are several important limitations to all of these retrospective studies. First, in the studies by Gettings and colleagues [31] and Liu and colleagues [35], BUN was used as a surrogate measure for duration of $\mathrm{AKI}$. However, BUN is an imperfect surrogate for time. Urea generation is not constant between patients, or even within an individual patient over time, and the volume of distribution of urea may change over time. As a result, the rate of increase in BUN varies between patients, and may not even be constant in an individual patient over time. Second is the issue of bias by indication. Renal support was initiated for oliguria in the 'early' groups and for azotemia or hyperkalemia in the 'late' groups in both of the post-cardiac surgery studies [32,33]. Although the reasons for 'early' and 'late' initiation of treatment in the studies by Gettings and colleagues [31] and Liu and colleagues [35] were not specified, it is likely earlier initiation was prompted by volume overload and electrolyte disturbances whereas late initiation of therapy was more likely to be prompted by progressive azotemia. Whether there is a relationship between indication for therapy and outcome is not known. Most importantly, the design of all four of these studies limited analysis to patients who received renal replacement therapy, ignoring the subset of patients with AKI who recover or die without RRT.

A single study has attempted to address the timing of CRRT prospectively. Bouman and colleagues [12] randomized 106 critically ill patients with $\mathrm{AKI}$ at two centers to three groups: early high-volume CVVH $(n=35)$, early low-volume CVVH $(n=35)$ and late low-volume CVVH $(n=36)$. Treatment was initiated in the two early groups within 12 hours of meeting study inclusion criteria, which included the presence of oliguria for more than 6 hours despite hemodynamic optimization or a measured creatinine clearance of less than $20 \mathrm{ml} /$ minute on a 3 hour timed urine collection. In the late group, renal support was not initiated until the BUN was more than $112 \mathrm{mg} / \mathrm{dl}$, potassium was more than $6.5 \mathrm{mEq} / \mathrm{l}$, or pulmonary edema was present. No significant differences in survival were observed between the three groups. Of note, however, the overall 28 day mortality for subjects in this study was only $27 \%$, substantially lower than mortality rates reported in most other studies of critically ill patients with AKI, suggesting a lower disease burden in this cohort. In addition, as a result of the small sample size, the statistical power of the study was low, meaning that there is a high likelihood of 
Critical Care Vol 11 No 6 Palevsky

Table 2

\begin{tabular}{|c|c|c|c|c|c|c|}
\hline \multirow[b]{2}{*}{ Study } & \multirow[b]{2}{*}{ Year } & \multirow[b]{2}{*}{$\mathrm{N}$} & \multicolumn{2}{|c|}{ Effluent flow rate $(\mathrm{ml} / \mathrm{kg} / \mathrm{h})$} & \multicolumn{2}{|c|}{ Survival (percent) } \\
\hline & & & Low dose & High dose & Low dose & High dose \\
\hline Ronco et al. [9] & 2000 & 435 & 20 & $\begin{array}{l}35 \\
45\end{array}$ & 41 & $\begin{array}{l}57 \\
58\end{array}$ \\
\hline Bouman et al. [12] & 2002 & 106 & 19 & 48 & 72 & 74 \\
\hline Saudan et al. [10] & 2006 & 206 & 25 & 42 & 39 & 59 \\
\hline
\end{tabular}

type II error. It is also important to note that 6 of the 36 patients $(16.7 \%)$ in the late therapy group never received RRT, 2 patients because they died prior to meeting criteria for RRT and 4 patients because they recovered renal function.

Thus, current data remain inadequate to answer the question of appropriate indications and timing of initiation of CRRT in AKI. The vast majority of patients with AKI are never treated with RRT, yet have increased mortality rates [36]. Whether earlier initiation of RRT, regardless of modality, or provision of therapy in patients currently managed conservatively, improves survival remains an open question. Would this strategy improve outcomes, or does the observational data suggesting improved outcomes merely reflect inclusion of patients with a lesser degree of organ injury, whose outcomes would be better regardless of treatment strategy? Ultimately, the answer will require data from a prospective randomized trial. However, the design of such a trial poses significant challenges; most critically, the need for early identification of patients who will have persistent and severe renal injury. Without reliable markers to identify this population, a substantial number of patients who would not otherwise be started on RRT will need to be randomized into an early therapy arm and subjected to the risks of RRT. Thus, robust biomarkers and/or clinical predictors of the course of $\mathrm{AKI}$ are needed before such a study can be undertaken.

\section{Dose of continuous renal replacement therapy} Three randomized controlled trials have assessed the relationship between dose of CRRT and outcomes of AKI (Table 2) [9,10,12]. Since the clearance of low molecular weight solutes during CRRT closely approximates total effluent flow, the dose of therapy can be quantified in terms of the sum of the ultrafiltrate and dialysate flow rates. Ronco and colleagues [9] randomized 425 critically ill patients with AKI treated using $\mathrm{CVVH}$ at a single center to ultrafiltration rates of 20,35 or $45 \mathrm{ml} / \mathrm{kg} / \mathrm{h}$. Survival 15 days after discontinuation of CRRT was $41 \%$ in the lowest dose arm compared to $57 \%$ and $58 \%$ in the intermediate and highest dose arms, respectively $(p<0.001)$. There was no difference in recovery of renal function between groups, with greater than $90 \%$ of surviving patients having full recovery of renal function 15 days after discontinuation of CRRT; among non-survivors, approximately $20 \%$ of patients had recovered renal function at time of death.

In contrast, Bouman and colleagues [12] observed no improvement in survival with high volume hemofiltration $(3 \mathrm{l} / \mathrm{h}$; median, $48 \mathrm{ml} / \mathrm{kg} / \mathrm{h}$ )) compared to low volume hemofiltration ( 1 to $1.5 \mathrm{l} / \mathrm{h}$; median, $19 \mathrm{ml} / \mathrm{kg} / \mathrm{h}$ ) in their previously described study of 106 subjects randomized to early high-volume, early low-volume or late low-volume CVVH. However, as previously noted, with 106 patients divided between three treatment arms, the negative result does not have sufficient statistical power to demonstrate equivalence.

More recently, Saudan and colleagues [10] reported the results of a single center randomized trial comparing $\mathrm{CVVH}$ $(n=102)$ with a mean ultrafiltration rate of $25 \pm 5 \mathrm{ml} / \mathrm{kg} / \mathrm{h}$ to CVVHDF $(n=104)$ with a mean total effluent flow rate of $42 \mathrm{ml} / \mathrm{kg} / \mathrm{h}$ (mean ultrafiltration rate of $24 \pm 6 \mathrm{ml} / \mathrm{kg} / \mathrm{h}$; mean dialysate flow rate of $15 \pm 5 \mathrm{ml} / \mathrm{kg} / \mathrm{h}$ ). Survival after 28 days was $39 \%$ in the CVVH group and $59 \%$ in the CVVHDF $(p=0.03)$ and $34 \%$ and $59 \%$, respectively, after 90 days $(p=0.0005)$. Recovery of renal function was not different between the two groups, with $71 \%$ of surviving patients recovering renal function by day 90 in the CVVH group compared to $78 \%$ in the CVVHDF group. Although on superficial consideration this study might be interpreted as a comparison of modality of CRRT, it is more appropriate to consider it as a dosing study. In the CVVHDF group, diffusive clearance was added to an essentially constant dose of hemofiltration, increasing total effluent flow rate by more than $70 \%$. For this to have been a pure comparison of modality, without influence of dose, the total effluent flow rate in the two treatment arms would have needed to be constant. Rather, this study suggests that augmentation of small solute clearance is associated with improved survival. As with other single center studies, the results of this study should be interpreted with caution, particularly since the investigators were not blinded to treatment group assignment. 
Several studies have suggested benefit with even higher doses of convective therapy (for example, high volume hemofiltration) in patients with sepsis $[9,37,38]$. These investigators have postulated that removal of humoral mediators modulate the inflammatory response in patients with severe sepsis. The data from these studies are not sufficiently robust, however, to draw any definitive conclusions.

Two large multicenter randomized controlled trials addressing intensity of renal support in AKI are currently under way $[39,40]$. In the United States, the VA/NIH Acute Renal Failure Trial Network (ATN) Study comparing two strategies for the intensity of renal support recently concluded subject enrollment $[39,40]$. In both treatment arms, patients received IHD when they were hemodynamically stable and either CVVHDF or sustained low-efficiency dialysis (SLED) when they were hemodynamically unstable. In the intensive therapy arm, IHD and SLED were provided six-times per week and CVVHDF at a total effluent flow rate of $35 \mathrm{ml} / \mathrm{kg} / \mathrm{h}$. In the lowdose arm, IHD and SLED were provided three-times per week and the effluent flow during CVVHDF was $20 \mathrm{ml} / \mathrm{kg} / \mathrm{h}$. With an enrollment of 1,124 patients, the ATN study has $>90 \%$ power to detect a reduction in mortality from $55 \%$ to $45 \%$ at a two-sided significance level of 0.05. In Australia and New Zealand, the Randomized Evaluation of Normal versus Augmented Level of RRT (RENAL) study is randomizing patients treated with CVVHDF to effluent flow rates of either 25 or $40 \mathrm{ml} / \mathrm{kg} / \mathrm{h}$ [40]. The RENAL study will randomize 1,500 patients, providing $90 \%$ power to detect a reduction in mortality from $60 \%$ to $51.5 \%$ with a two-sided significance level of 0.05 . It is scheduled to conclude enrollment in late 2007 or early 2008. When completed, these two studies should provide high quality evidence regarding dosing strategies for renal support in AKI.

\section{Conclusion}

The optimal timing for initiation of RRT in patients with AKI is uncertain. Although several observational and retrospective analyses have suggested improved survival with earlier initiation of renal support, the exclusion of patients with AKI who meet criteria for early initiation of RRT but never receive therapy limits the validity of these analyses. Unfortunately, however, this question will probably not be able to be definitively answered in a prospective randomized controlled trial until more robust biomarkers and/or clinical predictors of the course of $\mathrm{AKI}$ are available. Although multiple clinical

This article is part of a review series on Renal replacement therapy, edited by John Kellum and Lui Forni.

Other articles in the series can be found online at http://ccforum.com/articles/

theme-series.asp?series=CC_Renal trials have suggested an improvement in survival with higher doses of CRRT, results have not been consistent across all studies. Two large randomized clinical trials are currently underway that should provide high quality evidence regarding the optimal dosing of renal support in AKI.

\section{Competing interests}

PMP is the Study Chairman of the VA/NIH Acute Renal Failure Trial Network Study. He declares that he has no other competing interests.

\section{References}

1. Levy EM, Viscoli CM, Horwitz Rl: The effect of acute renal failure on mortality. A cohort analysis. JAMA 1996, 275:14891494.

2. Bates DW, Su L, Yu DT, Chertow GM, Seger DL, Gomes DR, Platt R: Correlates of acute renal failure in patients receiving parenteral amphotericin B. Kidney Int 2001, 60:1452-1459.

3. Chertow GM, Levy EM, Hammermeister KE, Grover F, Daley J: Independent association between acute renal failure and mortality following cardiac surgery. Am J Med 1998, 104:343348.

4. Metnitz PG, Krenn CG, Steltzer H, Lang T, Ploder J, Lenz K, Le Gall JR, Druml W: Effect of acute renal failure requiring renal replacement therapy on outcome in critically ill patients. Crit Care Med 2002, 30:2051-2058.

5. Chertow GM, Burdick E, Honour M, Bonventre JV, Bates DW: Acute kidney injury, mortality, length of stay, and costs in hospitalized patients. J Am Soc Nephrol 2005, 16:3365-3370.

6. Liano F, Junco E, Pascual J, Madero R, Verde E: The spectrum of acute renal failure in the intensive care unit compared with that seen in other settings. The Madrid Acute Renal Failure Study Group. Kidney Int Supp/ 1998, 66:S16-24.

7. Liano F, Pascual J: Epidemiology of acute renal failure: a prospective, multicenter, community-based study. Madrid Acute Renal Failure Study Group. Kidney Int 1996, 50:811818.

8. Uchino S, Kellum JA, Bellomo R, Doig GS, Morimatsu H, Morgera $\mathrm{S}$, Schetz M, Tan I, Bouman C, Macedo $\mathrm{E}$, et al:: Acute renal failure in critically ill patients: a multinational, multicenter study. JAMA 2005, 294:813-818.

9. Ronco C, Bellomo R, Homel P, Brendolan A, Dan M, Piccinni P, La Greca G: Effects of different doses in continuous venovenous haemofiltration on outcomes of acute renal failure: a prospective randomised trial. Lancet 2000, 356:26-30.

10. Saudan P, Niederberger M, De Seigneux S, Romand J, Pugin J, Perneger T, Martin PY: Adding a dialysis dose to continuous hemofiltration increases survival in patients with acute renal failure. Kidney Int 2006, 70:1312-1317.

11. Schiffl H, Lang SM, Fischer R: Daily hemodialysis and the outcome of acute renal failure. $N$ Engl J Med 2002, 346:305-310.

12. Bouman CS, Oudemans-Van Straaten HM, Tijssen JG, Zandstra DF, Kesecioglu J: Effects of early high-volume continuous venovenous hemofiltration on survival and recovery of renal function in intensive care patients with acute renal failure: a prospective, randomized trial. Crit Care Med 2002, 30:22052211.

13. Overberger $P$, Pesecreta M, Palevsky $P$ : Management of renal replacement therapy in acute kidney injury: A survey of practitioner prescribing practices. Clin J Am Soc Nephrol 2007, 2:in press.

14. Mehta RL, McDonald B, Gabbai FB, Pahl M, Pascual MT, Farkas A, Kaplan RM: A randomized clinical trial of continuous versus intermittent dialysis for acute renal failure. Kidney Int 2001, 60:1154-1163.

15. Augustine JJ, Sandy D, Seifert TH, Paganini EP: A randomized controlled trial comparing intermittent with continuous dialysis in patients with ARF. Am J Kidney Dis 2004, 44:1000-1007.

16. Uehlinger DE, Jakob SM, Ferrari $P$, Eichelberger M, Huynh-Do U, Marti HP, Mohaupt MG, Vogt B, Rothen HU, Regli B, et al.: Comparison of continuous and intermittent renal replacement therapy for acute renal failure. Nephrol Dial Transplant 2005, 20:1630-1637. 
17. Vinsonneau C, Camus $C$, Combes A, Costa de Beauregard MA, Klouche K, Boulain T, Pallot JL, Chiche JD, Taupin P, Landais P, Dhainaut JF: Continuous venovenous haemodiafiltration versus intermittent haemodialysis for acute renal failure in patients with multiple-organ dysfunction syndrome: a multicentre randomised trial. Lancet 2006, 368:379-385.

18. Kellum J, Palevsky PM: Renal support in acute kidney injury. Lancet 2006, 368:344-345.

19. Palevsky PM: Dialysis modality and dosing strategy in acute renal failure. Semin Dial 2006, 19:165-170.

20. Rondon-Berrios H, Palevsky PM: Treatment of acute kidney injury: an update on the management of renal replacement therapy. Curr Opin Nephrol Hypertens 2007, 16:64-70.

21. Ronco C: Continuous dialysis is superior to intermittent dialysis in acute kidney injury of the critically ill patient. Nat Clin Pract Nephrol 2007, 3:118-119.

22. Himmelfarb J: Continuous dialysis is not superior to intermittent dialysis in acute kidney injury of the critically ill patient. Nat Clin Pract Nephrol 2007, 3:120-121.

23. Teschan P, Baxter C, O'Brian T, Freyhof J, Hall W: Prophylactic hemodialysis in the treatment of actue renal failure. Ann Intern Med 1960, 53:992-1016.

24. Teschan PE: Acute renal failure during the Korean War. Ren Fail 1992, 14:237-239.

25. Parsons FM, Hobson SM, Blagg CR, Mc CB: Optimum time for dialysis in acute reversible renal failure. Description and value of an improved dialyser with large surface area. Lancet 1961, 1:129-134.

26. Fischer RP, Griffen WO Jr, Reiser M, Clark DS: Early dialysis in the treatment of acute renal failure. Surg Gynecol Obstet 1966, 123:1019-1023.

27. Kleinknecht D, Jungers P, Chanard J, Barbanel C, Ganeval D: Uremic and non-uremic complications in acute renal failure: Evaluation of early and frequent dialysis on prognosis. Kidney Int 1972, 1:190-196.

28. Conger JD: A controlled evaluation of prophylactic dialysis in post-traumatic acute renal failure. J Trauma 1975, 15:10561063.

29. Gillum DM, Dixon BS, Yanover MJ, Kelleher SP, Shapiro MD, Benedetti RG, Dillingham MA, Paller MS, Goldberg JP, Tomford $\mathrm{RC}$, et al:: The role of intensive dialysis in acute renal failure. Clin Nephrol 1986, 25:249-255.

30. Conger J: Does hemodialysis delay recovery from acute renal failure. Semin Dial 1990, 3:146-148.

31. Gettings LG, Reynolds HN, Scalea T: Outcome in post-traumatic acute renal failure when continuous renal replacement therapy is applied early versus late. Intensive Care Med 1999, 25:805-813.

32. Demirkilic U, Kuralay E, Yenicesu M, Caglar K, Oz BS, Cingoz F, Gunay C, Yildirim V, Ceylan S, Arslan M, et al.: Timing of replacement therapy for acute renal failure after cardiac surgery. J Card Surg 2004, 19:17-20.

33. Elahi MM, Lim MY, Joseph RN, Dhannapuneni RR, Spyt TJ: Early hemofiltration improves survival in post-cardiotomy patients with acute renal failure. Eur J Cardiothorac Surg 2004, 26: 1027-1031.

34. Piccinni P, Dan M, Barbacini S, Carraro R, Lieta E, Marafon S, Zamperetti N, Brendolan A, D'Intini V, Tetta C, et al.: Early isovolaemic haemofiltration in oliguric patients with septic shock. Intensive Care Med 2006, 32:80-86.

35. Liu KD, Himmelfarb J, Paganini E, Ikizler TA Soroko SH Mehta $\mathrm{RL}$, Chertow GM: Timing of initiation of dialysis in critically ill patients with acute kidney injury. Clin J Am Soc Nephrol 2006, 1:915-919.

36. Hoste EA, Clermont G, Kersten A, Venkataraman R, Angus DC, De Bacquer D, Kellum JA: RIFLE criteria for acute kidney injury are associated with hospital mortality in critically ill patients: a cohort analysis. Crit Care 2006, 10:R73.

37. Honore PM, Jamez J, Wauthier M, Lee PA, Dugernier T, Pirenne B, Hanique G, Matson JR: Prospective evaluation of short-term, high-volume isovolemic hemofiltration on the hemodynamic course and outcome in patients with intractable circulatory failure resulting from septic shock. Crit Care Med 2000, 28: 3581-3587.

38. Cole L, Bellomo R, Journois D, Davenport P, Baldwin I, Tipping P: High-volume haemofiltration in human septic shock. Intensive Care Med 2001, 27:978-986
39. Palevsky PM, O'Connor T, Zhang JH, Star RA, Smith MW: Design of the VA/NIH Acute Renal Failure Trial Network (ATN) Study: intensive versus conventional renal support in acute renal failure. Clin Trials 2005, 2:423-435.

40. Bellomo R: Do we know the optimal dose for renal replacement therapy in the intensive care unit? Kidney Int 2006, 70: 1202-1204. 